\title{
The History of Science as a Graveyard of Theories: A Philosophers' Myth?
}

\author{
Moti Mizrahi
}

Florida Institute of Technology

\begin{abstract}
According to the antirealist argument known as the pessimistic induction, the history of science is a graveyard of dead scientific theories and abandoned theoretical posits. Support for this pessimistic picture of the history of science usually comes from a few case histories, such as the demise of the phlogiston theory and the abandonment of caloric as the substance of heat. In this paper, I wish to take a new approach to examining the "history of science as a graveyard of theories" picture. Using JSTOR Data for Research and Springer Exemplar, I present new lines of evidence that are at odds with this pessimistic picture of the history of science. When rigorously tested against the historical record of science, I submit, the pessimistic picture of the history of science as a graveyard of dead theories and abandoned posits may turn out to be no more than a philosophers' myth.
\end{abstract}

Keywords: antirealism; history of science; no-miracles argument; pessimistic induction; scientific realism

\section{Introduction}

The picture of the "history of science [as] a graveyard of theories that were empirically successful for a time, but are now known to be false, and of theoretical entities - the crystalline spheres, phlogiston, caloric, the ether and their ilk - that we now know do not exist" (Lipton $2005,1265)$ is quite popular among historians and philosophers of science. Historians and philosophers of science often talk about the "the historical graveyard of science" (Frost-Arnold 2011,1138 ) and the history of science as a "cemetery of theories" (Stengers 2000, 31). Here is some additional textual evidence for the popularity of the "the history of science is a graveyard of dead scientific theories and abandoned theoretical posits" picture (henceforth, the "graveyard picture") among historians and philosophers of science:

- "[T]he history of science looks like a graveyard of dead epistemic objects" (Chang 2011, 426).

- "There is a graveyard of explanations founded on phlogiston, coronium, and ether" (Sorensen 2013, 31).

- "[T]he history of science offers a graveyard of theories and prefigures the doom of every scientific theory we hold dear" (Graham 2013, 22).

- " $[\mathrm{H}]$ istory is a graveyard of abandoned scientific methods, theories, ideas, and attitudes" (Harker 2015, 92). 
- "The history of science is a graveyard of theories that "worked" but have since been replaced" (Harrison 2015, 181).

In fact, the "graveyard picture" even made it into popular media (Schulz 2011). This pessimistic picture is supposed to provide the basis for an inductive argument "whose conclusion is that current theories are likely future occupants of the same graveyard" (Chakravartty 2008, 152). This inductive basis for this conclusion is usually taken to be a list that Laudan complied in his $(1981,33)$, which includes twelve dead theories and abandoned theoretical posits, such as the phlogiston theory of chemistry, the caloric theory of heat, and the electromagnetic aether. ${ }^{1}$ follows:

Roughly put, then, the pessimistic induction is an argument that is supposed to proceed as

1. Throughout the history of science, most scientific theories and theoretical posits ended up in the graveyard.

Therefore, probably,

2. Most scientific theories and theoretical posits (including current ones) will end up in the graveyard. $^{2}$

It is important to emphasize that the "graveyard picture" must be taken as asserting that most scientific theories and theoretical posits of the past ended up in the graveyard for the pessimistic induction to be a strong inductive argument. In other words, it would be significantly more likely that a current theoretical posit, $t$, will end up in the graveyard (i.e., be abandoned) only if most theoretical posits in the history of science ended up in the graveyard (i.e., were abandoned). If only some theoretical posits were abandoned in the past, it would not significantly raise the probability that any given current theoretical posit will be abandoned (Mizrahi 2013, 32163220).

However, as Park (2011) argues, since Laudan's list is not a random sample of scientific theories, which means that it cannot be a representative sample of scientific theories, any inductive argument that is based on Laudan's list commits the fallacy of biased statistics. That is to say, an inductive argument from a sample that is based on Laudan's list is a bad inductive generalization because it is based on "biased statistics" (Park 2011, 82), because "the joint sample set of all examples of refuted theories offered by antirealists is not representative" (Fahrbach 2011, 151), and because the "theories on Laudan's list were not randomly selected,

\footnotetext{
${ }^{1}$ Vickers (2013) attempts to offer a new and improved list of twenty dead theories and abandoned posits. For a critical evaluation of Vickers' argument as either a deductive or an inductive argument, see my (2015b).

${ }^{2}$ It should be noted that some interpret the pessimistic induction as a deductive argument, specifically a reductio of the realist view that (novel) predictive success is a mark of (approximate) truth. See, e.g., Lewis (2001) and Lange (2002). Saatsi (2005) accepts the reductio formulation of the pessimistic induction, but supplements it with a statistical inference. For a critical evaluation of the pessimistic induction as either a deductive (reductio and argument from counterexamples) or an inductive argument (inductive generalization from a sample), see my (2013) and (2015b).
} 
but rather were cherry-picked in order to argue against a thesis of scientific realism" (Mizrahi 2013, 3220). ${ }^{3}$

Park, Fahrbach, and my criticisms notwithstanding, the pessimistic induction is still a popular argument in the scientific realism/antirealism debate (see, e.g., Frost-Arnold 2014, Müller $2015^{4}$, Saatsi 2015 and Wray 2015 for recent discussions of the argument). ${ }^{5}$ Given its enduring popularity, then, I wish to take a new approach to examining the "graveyard picture." Using JSTOR's Data for Research and Springer Exemplar, I will present new lines of evidence that are at odds with the "graveyard picture." That is to say, the patterns that I will uncover are not what we would expect if the history of science were indeed a graveyard of dead scientific theories and abandoned theoretical posits. When rigorously tested against the historical record of science, then, the "graveyard picture" may turn out to be no more than a philosophers' myth.

\section{New lines of evidence}

\section{2a. Random samples}

To avoid conformation bias and cherry picking data, we need to test the "graveyard picture" against the historical record of science. Fortunately, in the literature on scientific realism we can find work that exemplifies a much more rigorous methodology of inductive argumentation than cherry picking. For instance, Fahrbach (2011) uses methods from bibliometrics to collect statistical evidence for what he calls "the exponential growth of science." Fahrbach's $(2011,149)$ bibliometric data show that Laudan's list is not a representative sample of scientific theories, given that "all entries on that list are theories that were abandoned more than 100 years ago [which is] during the time of the first $5 \%$ of all scientific work ever done by scientists" (cf. Wray 2013; see also Fahrbach 2016). In my own work, I have used random sampling to collect representative samples of scientific theories and scientific laws. My findings suggest that there are significantly more scientific theories are laws that are not considered strictly false by current practitioners in the relevant fields than theories and laws that are considered dead (Mizrahi 2013).

\footnotetext{
${ }^{3}$ In my (2013) I also argue that the pessimistic induction fails as a deductive argument (either a reductio or an argument from counterexamples). For other criticisms of the pessimistic induction, see Doppelt (2007) and Park (2014).

${ }^{4}$ Müller (2015) focuses on the pessimistic induction as a deductive argument (specifically, a reductio) rather than an inductive argument. In a footnote, Müller $(2015,410)$ comments on my (2013) and says that I focus on just two premises of the reductio formulation of the pessimistic induction to the exclusion of other premises. This is a curious remark for, to show that a deductive argument is unsound, it is enough to show that one premise is false. One need not show that all the premises are false. Müller also seems to forget that Saatsi $(2005,1092)$, whom he quotes favourably, says that the reductio formulation of the pessimistic induction needs to be supplemented with "a statistical argument." If that is correct, then Fahrbach, Park, and my criticisms against the inductive formulation of the pessimistic induction apply to the reductio formulation as well. In other words, insofar as the reductio formulation of the pessimistic induction relies on the "graveyard picture," any evidence that undermines the latter undermines former as well.

${ }^{5}$ See also Ruhmkorff (2014) who advances a "local" (as opposed to a "global") pessimistic induction.
} 
Wray $(2015,70)$ describes my work as "preliminary," and suggests that more work that employs my methodology needs to be done. As Wray $(2015,69-70)$ writes:

Recently, Mizrahi (2013, 3220-3221) has suggested a method for constructing a random sample. He has even provided preliminary reports of his samplings of successful theories and laws from the history of science. The results are more optimistic than proponents of the PI suggest (Mizrahi 2013, 3222). This is preliminary work, so it would be premature for us to settle the issue on the basis of Mizrahi's sample of 40 scientific theories and 40 alleged scientific laws.

What follows, then, can be construed as my answer to Wray's call for more work that uses my methodology.

The methodology I have proposed in my (2013) consists in searching through reference works, such as Oxford's Dictionary of Chemistry (Rennie 2016), Oxford's Dictionary of Physics (Law and Rennie 2015), and The Oxford Companion to the History of Modern Science (Heilbron 2003), using Oxford Reference (oxfordreference.com), for terms, such as 'theory', 'entity', and 'posit', and then using a random number generator to collect a random sample of theoretical posits from the search results. ${ }^{6}$ This methodology is better than cherry picking case histories of abandoned theories and/or theoretical posits, since "the clue to reliable inductive generalizations is finding a sample that is representative of the population" (Govier 2013, 259).

By applying my methodology, we can collect a random sample of theoretical posits like the one in Table 1. To collect this random sample, I have searched for the terms 'theory', 'entity', and 'posit' in the Oxford's Dictionary of Chemistry, the Oxford's Dictionary of Physics, and The Oxford Companion to the History of Modern Science, using Oxford Reference (oxfordreference.com). My search yielded 1,046 entries in total. Of these 1,046 entries, I have collected a random sample of 40 entries using a random number generator. I then divided the entries into accepted posits, abandoned posits, and posits whose ontological status is debatable.

As we can see from Table 1, although there are some theoretical posits that were abandoned, and some theoretical posits whose ontological status is in question, most of the theoretical posits in this random sample were not abandoned and are not considered non-existent by current scientific lights.

\footnotetext{
${ }^{6}$ It is important to note that The Oxford Companion to the History of Modern Science covers "the period from the Renaissance to the early twenty-first century" and that the articles in it "cover all disciplines, historical periods, concepts, and methodologies" (Oxford Reference 2003). Moreover, the Oxford's Dictionary of Chemistry and the Oxford's Dictionary of Physics also contain entries on discarded scientific theories and abandoned theoretical posits, some of which turned up in the random sample listed in Table 1, such as caloric theory and phlogiston.
} 
Table 1. A random sample of forty theoretical posits (source: Oxford Reference)

\begin{tabular}{|l|l|l|l|}
\hline Accepted posits & $\begin{array}{l}\text { Abandoned } \\
\text { posits }\end{array}$ & Debated posits \\
\hline & $\begin{array}{l}\text { electron density, cell, spinor, polar bond, } \\
\text { valence bonds, mesomerism, covalent bonds, } \\
\text { chromophore, leptons, quarks, ionization } \\
\text { energy, wave packet, Donnan equilibrium, } \\
\text { electric potential, polar lipid, oxidation, } \\
\text { molecular orbital, excitation energy, enzyme, } \\
\text { resonance, ion atmosphere, chiral group, } \\
\text { isotope, photon, electrons, counterions, ion pair, } \\
\text { radical ion, atom, ion, molecule, energy transfer }\end{array}$ & $\begin{array}{l}\text { ether, } \\
\text { absolute } \\
\text { space, } \\
\text { epigenesis }\end{array}$ & $\begin{array}{l}\text { preons, } \\
\text { supermembrane, } \\
\text { jumping genes, } \\
\text { multiverse, } \\
\text { superstrings }\end{array}$ \\
\hline TOTAL & 32 & 3 & 5 \\
\hline
\end{tabular}

Clearly, this random sample does not support any pessimistic inductive inferences about scientific theories and theoretical posits in general, given that 32 of the 40 theoretical posits in this random sample (i.e., $80 \%$ ) were $n o t$ abandoned and are not considered non-existent by current scientific lights. In particular, this random sample does not support the inductive premise of the pessimistic induction, according to which "Throughout the history of science, most scientific theories and theoretical posits ended up in the graveyard."

This result (namely, that a random sample of scientific theories and theoretical posits does not contain significantly more abandoned than non-abandoned theories and posits) can be independently confirmed by applying the same methodology to other data sets. Springer Exemplar (springerexemplar.com), which is a tool for searching Springer's collection of 3,500 journals and 200,000 books for terms in context, is a useful tool for this purpose. Springer Exemplar allows us to look at terms in the context in which they occur. ${ }^{7}$ Table 2 shows that, using Springer Exemplar, a search through journal articles in the Life Sciences category, in the context of the terms 'posit', 'posited', and 'positing', which yielded 987 matching articles from

\footnotetext{
${ }^{7}$ According to the About page of Springer Exemplar (2017), this tool "searches more than 3,500 journals and close to 200,000 books from Springer's collection to find authentic examples of how a word or phrase is used in published literature. Comprehensive coverage includes both current and archival content in all major subject areas including the life science, medicine, engineering, mathematics, computer science, business, and law, contributed by some of the world's leading academics in these fields. Exemplar is continuously updated with new content as it is published." According to Springer (2017), their book archives provide "access to scholarly research published in books dating back to the 1840s." This should help address any concerns about how representative the Springer database is. In that respect, it is worth noting that, even if the Springer database did not contain publications going as far back as the 1840s, it could still be considered representative of scientific literature as a whole, given that "half of all scientific work ever done was done in the last 15-20 years, while the other half was done in all the time before; and three quarters of all scientific work ever done was done in the last 30-40 years, while in all the time before that, only one quarter was done" (Fahrbach 2011, 148).
} 
1982 to 2016, turned up more than twice as many contemporary posits (32) as Laudan's list of abandoned posits (12).

Table 2. A random sample of 50 search results for posit in the Life Science category yields 32 current theoretical posits (Source: Springer Exemplar)

\begin{tabular}{|l|l|}
\hline & Current theoretical posits in search results \\
\hline & $\begin{array}{l}\text { taxon, natural selection, mitochondria, metabolism, mental grammars, } \\
\text { phylogenesis, peptides, primordial folds, homeostasis, hemoglobin, animal } \\
\text { cognition, adaptive biases, parasitism, evolved self-fertility, evolution, somatic } \\
\text { cells, metabolites, pathogens, reactive nitrogen species (RNS), reactive oxygen } \\
\text { species (ROS), El Niño-Southern Oscillation (ENSO), Blastocystis, symbiosis, } \\
\text { red blood cells, adaptation, temporal heterogeneity, somatic mutation, } \\
\text { ribosome, biogenesis, Pak action, kinase domain, proteins }\end{array}$ \\
\hline TOTAL & 32 \\
\hline
\end{tabular}

If the history of science were really a graveyard of dead scientific theories and abandoned theoretical posits, we would expect the list of abandoned posits, like Laudan's list, to be much longer than the list of currently accepted posits. But that is not what we actually find. In fact, the list of current theoretical posits has more than three times the items than the list of abandoned theoretical posits, despite the fact that it consist of items from the life science alone. Even compared to Vickers' (2013) new and improved list of twenty dead theories and abandoned posits, the list of current posits in Table 2 is longer, despite being generated by a search using Springer Exemplar (as opposed to deliberately cherry picked) and being restricted to fifty random search results in the Life Sciences category, which is not what we would expect if the "graveyard picture" were an accurate picture of the historical record of science.

We can run similar searches in other categories on Springer Exemplar. For instance, let's look at a sample of 50 search results from journal articles in Physics. Table 3 shows that, using Springer Exemplar, a search through journal articles in the Physics category, in the context of the terms 'posit', 'posited', and 'positing', which yielded 191 matching articles from 1983 to 2016, turned up more than three times as many contemporary posits (42) as Laudan's list of abandoned posits (12). 
Table 3. A random sample of 50 search results for posit in the Physics category yields 42 current theoretical posits (Source: Springer Exemplar)

\begin{tabular}{|l|l|}
\hline & Current theoretical posits in search results \\
\hline & $\begin{array}{l}\text { wave function, quantum states, forces, atoms, potential energy, momentum, } \\
\text { cells, singularity, spacetime, multiverse, curvature, vacuum fluctuations, fields, } \\
\text { energy, bonds, ions, gravity, dimensions, superposition, branching worlds, } \\
\text { torsion tensor, lattice parameters, neurons, electrical signals, Higgs boson, } \\
\text { Higgs field, fermions, superconductivity, Cooper pairs, electrons, thermal } \\
\text { energy, ion pumps, Fermi arcs, spin, Yukawa interaction, nonlocality, } \\
\text { entanglement, positrons, solar energetic particles, solar flares, photons, entropy }\end{array}$ \\
\hline TOTAL & 42 \\
\hline
\end{tabular}

Again, if the history of science were really a graveyard of dead scientific theories and abandoned theoretical posits, we would expect the list of abandoned posits, like Laudan's list, to be much longer than the list of currently accepted posits. But that is not what we actually find. In fact, the list of current theoretical posits has more than three times the items than the list of abandoned theoretical posits, despite the fact that it consist of items from physics alone. Even compared to Vickers' (2013) new and improved list of twenty dead theories and abandoned posits, the list of current posits in Table 3 is longer, despite being generated by a search using Springer Exemplar (as opposed to deliberately cherry picked) and being restricted to fifty random search results in the Physics category, which is not what we would expect if the "graveyard picture" were an accurate picture of the historical record of science. explicitly:

Accordingly, it looks like the "graveyard picture" fails the test of random sampling. More

1. If the history of science were a graveyard of dead theories and abandoned posits, then random samples of scientific theories and theoretical posits would contain significantly more dead theories and abandoned posits than live theories and accepted posits.

2. It is not the case that random samples of scientific theories and theoretical posits contain significantly more dead theories and abandoned posits than live theories and accepted posits.

Therefore,

3. It is not the case that the history of science is a graveyard of dead theories and abandoned posits. $^{8}$

\footnotetext{
${ }^{8}$ Since this is a disconfirmation argument that proceeds from empirical evidence, in particular, random samples of scientific theories and theoretical posits, it should be clear that it is not meant to be a conclusive refutation of the "graveyard picture." Rather, it shows that the empirical evidence does not support the "graveyard picture." In other words, what we see in the historical record of science is not what we would expect to see if the "graveyard picture" were an accurate picture of the history of science.
} 
What these random samples show, I submit, is that for any example of a dead scientific theory or an abandoned theoretical posit one can cherry pick from the history of science, there are many more scientific theories and theoretical posits that are currently accepted by practitioners in the relevant scientific fields. If this is correct, then the "graveyard" may turn out to be no more than a small plot.

\section{2b. Bibliometric data}

Another way to test the "graveyard picture" against the historical record of science is to employ the techniques of bibliometrics (Fahrbach 2011, 146), in particular, techniques of detecting publication patterns. JSTOR's Data for Research (dfr.jstor.org), which contains data on articles published between 1545 and 2013, is a useful tool for this purpose. JSTOR Data for Research allows us to compare publication patterns of currently accepted theoretical posits and abandoned theoretical posits. For instance, it is often said that "the Chemical Revolution was the overthrow of the reigning 'phlogiston' theory and its replacement by a theory based on the role of oxygen" (Cohen 2001, 231). So let's look at phlogiston and oxygen. Figure 1 shows that, in the Biological Sciences subject in the JSTOR corpus (which contains 339,204 items), the proportion of publications in which the term 'oxygen' occurs has increased significantly since the $1800 \mathrm{~s}$ compared to the proportion of publications in which the term 'phlogiston' occurs.

Figure 1. Proportions of publications containing 'oxygen' versus 'phlogiston' in the JSTOR corpus (source: JSTOR Data for Research)

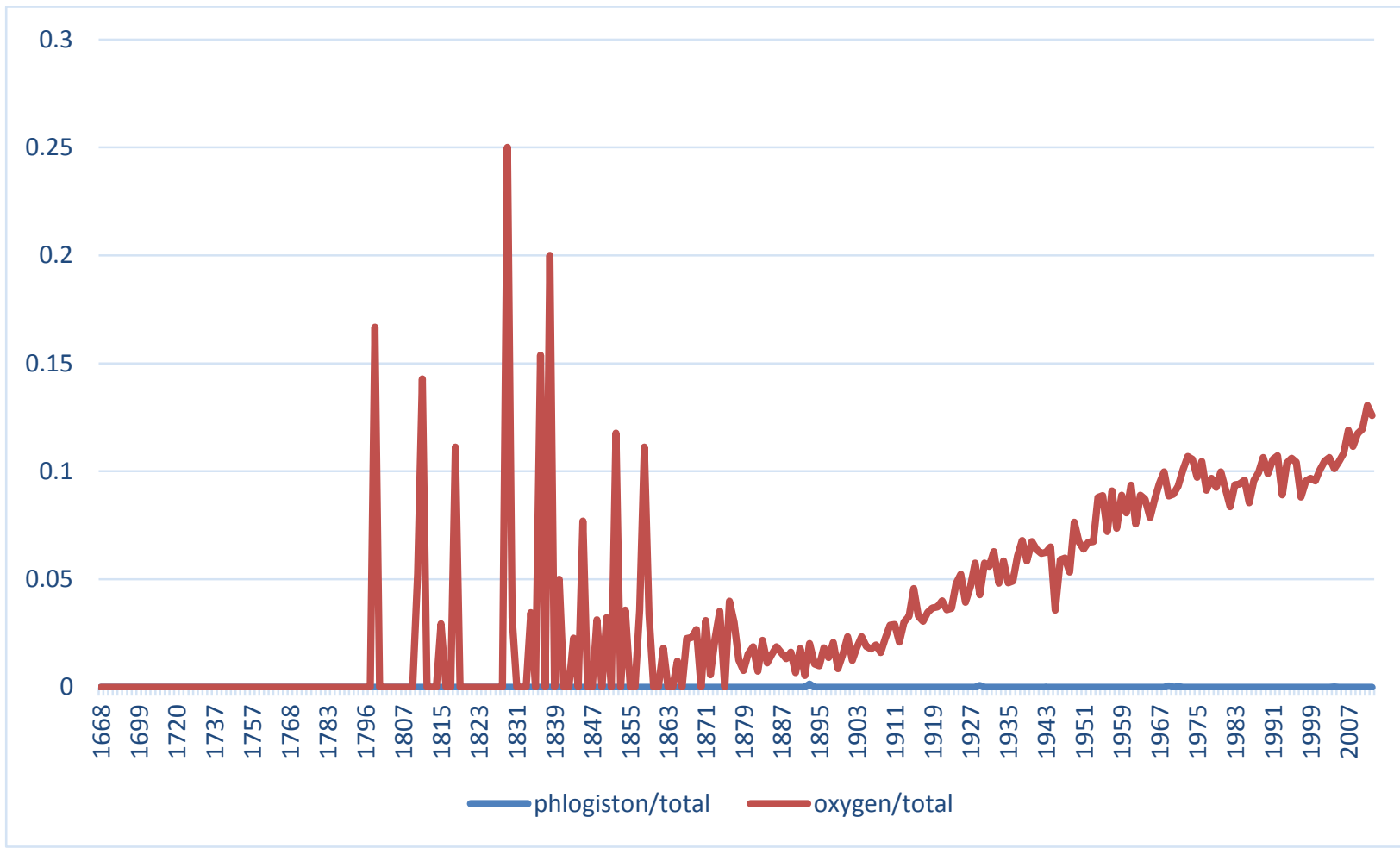


Similarly, Figure 2 shows that, in the Physics subject in the JSTOR corpus (which contains 169,612 items), the proportion of publications in which the term 'molecule' occurs has increased significantly since the 1800 s compared to the proportion of publications in which the term 'caloric' occurs. The few articles that contain the terms 'caloric' appear in journals that publish work in the history and philosophy of science, such as Isis and The British Journal for the History of Science, for the most part. I have restricted my searches to specific subjects, such as Biological Sciences and Physics, in order to avoid the HPS publications, but it appears that some of them made it into the search results in the Physics case, given that some of the articles that these journals publish are tagged "Physics" in the JSTOR database.

Figure 2. Proportions of publications containing 'molecule' versus 'caloric' in the JSTOR corpus (source: JSTOR Data for Research)

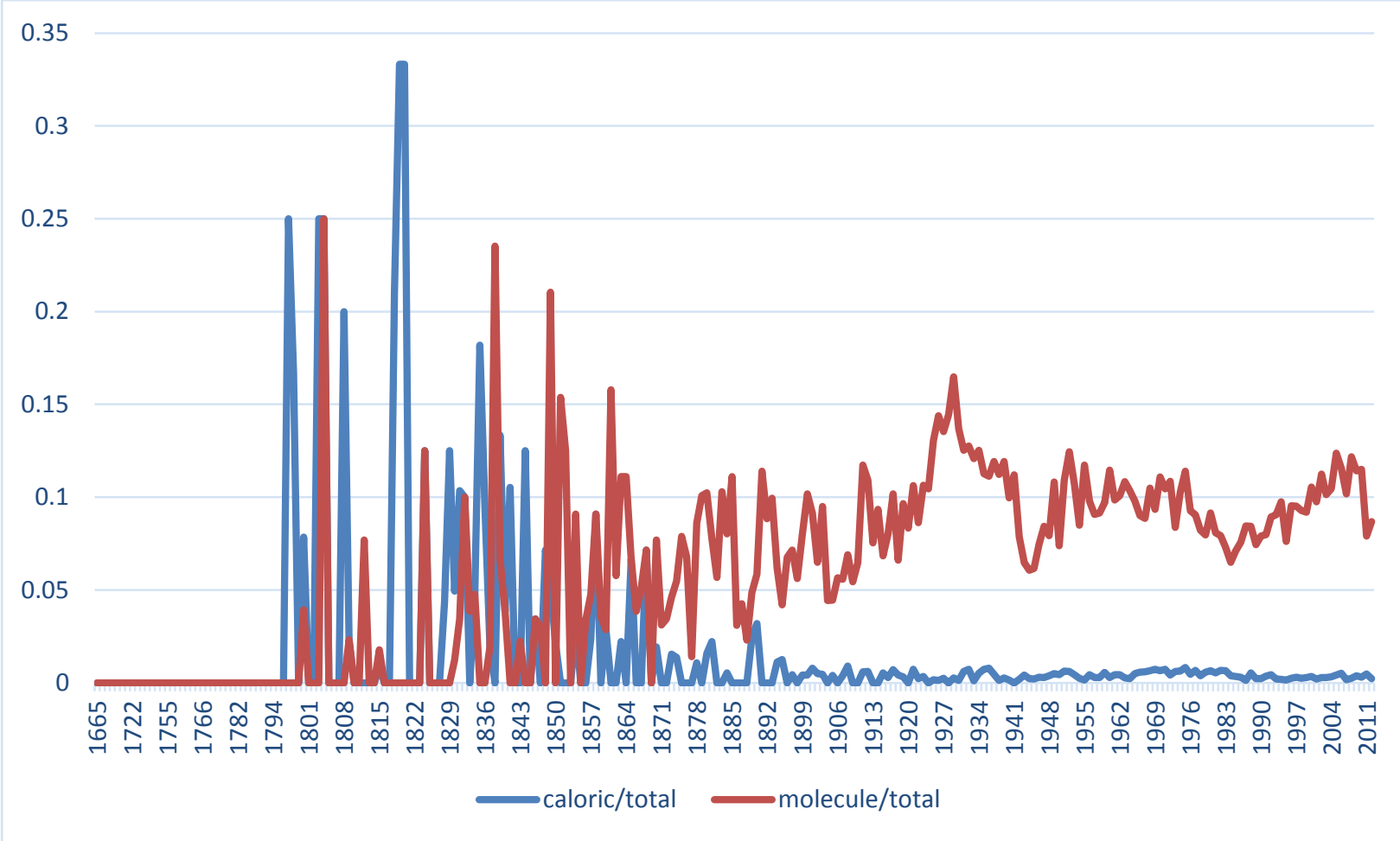

Likewise, in the Physics subject in the JSTOR corpus, the proportion of publications in which the term 'field' occurs has increased significantly since the 1800 s compared to the proportion of publications in which the term 'aether' occurs, as shown in Figure 3. The few articles that contain the terms 'caloric' appear in journals that publish work in the history and philosophy of science, such as Historical Studies in the Physical Sciences and The British Journal for the Philosophy of Science, for the most part. Again, I have restricted my searches to specific subjects, such as Biological Sciences and Physics, in order to avoid the HPS publications, but it appears that some of them made it into the search results in the Physics case, 
given that some of the articles that these journals publish are tagged "Physics" in the JSTOR database. At any rate, the JSTOR data show that, since 1995, more than 50\% of Physics publications each year contain the term 'field'.

Figure 3. Proportions of publications containing 'field' versus 'aether' in the JSTOR corpus (source: JSTOR Data for Research)

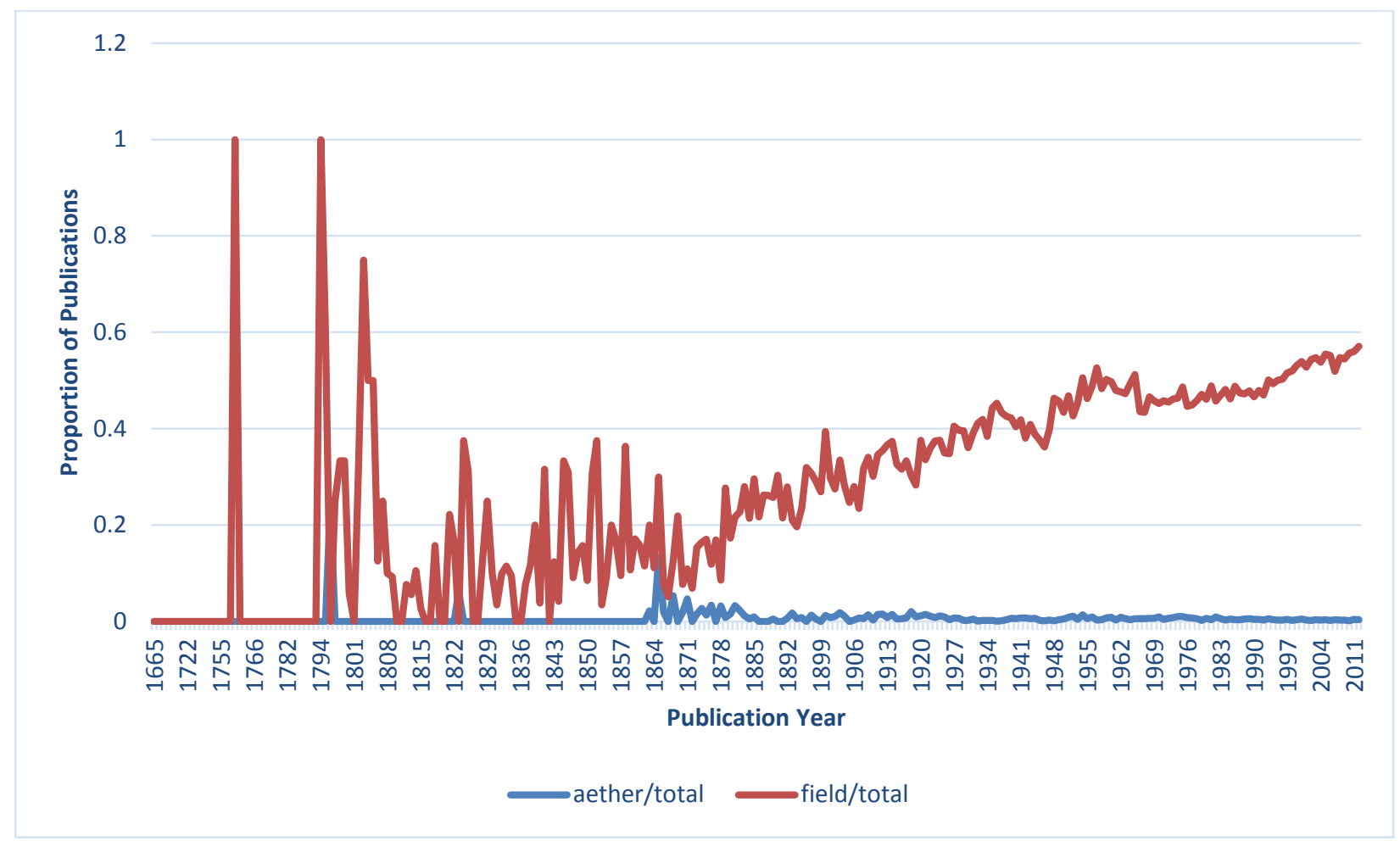

These publication patterns show that, while caloric and aether theories are dead research programs, molecular and field theories are alive and kicking (or "progressive," to use Lakatos' terminology). Likewise, phlogiston has flat-lined around the end of the 1700s, whereas oxygen is still going strong. These results are not logically inconsistent with the "graveyard picture," but they do challenge it. For if the history of science were really a graveyard of dead scientific theories and abandoned theoretical posits, we would not expect to see scientific theories and theoretical posit dominate the literature in a particular field for more than two centuries. If some scientific theories and theoretical posits continue to figure prominently in the scientific literature, one begins to wonder when it becomes unreasonable to expect that they will be abandoned. explicitly:

Accordingly, it looks like the "graveyard picture" fails the test of bibliometrics. More 
1. If the history of science were a graveyard of dead theories and abandoned posits, then there would be no dominant theoretical posits (i.e., theoretical posits that continue to figure prominently in the scientific literature).

2. There are dominant theoretical posits.

Therefore,

3. It is not the case that the history of science is a graveyard of dead theories and abandoned posits. ${ }^{9}$

What these publication patterns show, I submit, is that for any example of a dead scientific theory or an abandoned theoretical posit one can cherry-pick from the history of science, there are other scientific theories and theoretical posits that continue to figure prominently in the scientific literature for more than two centuries now.

It is possible, of course, that I have mined the JSTOR database just before oxygen, molecule, and field are about to be abandoned by the scientific community. This mere possibility claim needs no support from the history of science. Hardly anyone would doubt this possibility, just as hardly anyone would doubt the possibility that oxygen, molecule, and field will not be abandoned. The "graveyard picture," however, is supposed to be more than a mere possibility akin to a sceptical hypothesis. It is supposed to be an accurate picture of the actual historical record of science. Since the track record of theoretical posits like oxygen, molecule, and field is such that they continue to figure prominently in the scientific literature in the relevant disciplines, we have no empirical reason (as opposed to a reason that is grounded in mere possibilities) to think that they are likely to be abandoned. In other words, the JSTOR data do not support the prediction that theoretical posits like oxygen, molecule, and field will be abandoned, whereas the "graveyard picture" predicts that such theoretical posits will be abandoned. For this reason, the JSTOR data do not support the "graveyard picture."

\section{2c. Historical timelines}

Another way to see the stability of some theoretical posits is to use historical reference works, such as The Oxford Companion to the History of Modern Science, in order to construct timelines of theoretical posits "from birth to death." For instance, Figure 4 shows that phlogiston and caloric did not last for more than a century before they were abandoned (phlogiston from about 1703 until 1780 and caloric from about 1783 until 1850), whereas oxygen and molecule are still around after more than two centuries. Similarly, electromagnetic aether ${ }^{10}$ was around for less than half a century, whereas field (McMullin 2002) is going strong (dominating more than 50\%

\footnotetext{
${ }^{9}$ Since this is a disconfirmation argument that proceeds from empirical evidence, in particular, bibliometric data, it should be clear that it is not meant to be a conclusive refutation of the "graveyard picture." Rather, it shows that the empirical evidence does not support the "graveyard picture." In other words, what we see in the historical record of science is not what we would expect to see if the "graveyard picture" were an accurate picture of the history of science.

${ }^{10}$ If we look at aether as a theoretical posit, rather than the more narrow electromagnetic aether, then it has been around since Aristotle, in whose physics it is the element that pervades the spheres above the sublunary world (Varvoglis 2014).
} 
of research articles in Physics, as we have seen) for more than a century and a half. (See my $2015 b$ for additional timelines.)

Figure 4. Timelines of caloric, molecule, oxygen, and phlogiston (source: Oxford Reference)

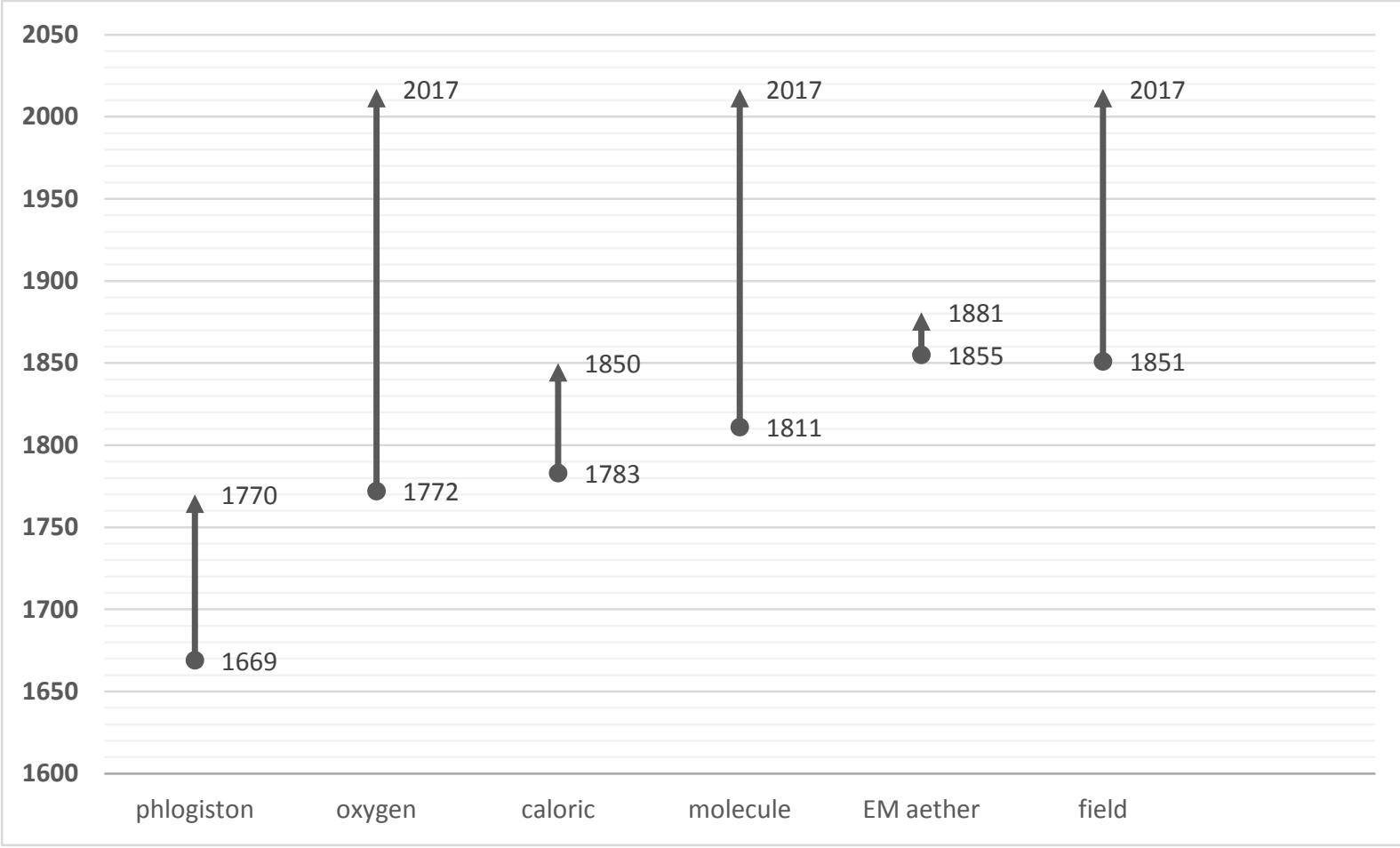

Accordingly, it looks like the "graveyard picture" fails the test of chronology. More explicitly:

1. If the history of science were a graveyard of dead theories and abandoned posits, then there would be no stable theoretical posits (i.e., theoretical posits that have been around for more than two centuries).

2. There are stable theoretical posits.

Therefore,

3. It is not the case that the history of science is a graveyard of dead theories and abandoned posits. $^{11}$

\footnotetext{
${ }^{11}$ Since this is a disconfirmation argument that proceeds from empirical evidence, in particular, chronological data, it should be clear that it is not meant to be a conclusive refutation of the "graveyard picture." Rather, it shows that the empirical evidence does not support the "graveyard picture." In other words, what we see in the historical record of science is not what we would expect to see if the "graveyard picture" were an accurate picture of the history of science.
} 
These chronological data, I submit, are not what we would expect if the history of science was indeed a graveyard of dead scientific theories and abandoned theoretical posits. That is to say, if the "graveyard picture" were an accurate picture of the history of science, we would expect to see most theoretical posits abandoned after a century or so, just as phlogiston and caloric were. However, the aforementioned chronological data show that there are some theoretical posits, like oxygen and molecule, that are at the centre of active research programs for more than two centuries now. To paraphrase Theodosius Dobzhansky, there are some theoretical posits without which nothing makes sense in the relevant field. This makes it less likely that such theoretical posits will be abandoned.

Antirealists may retort that we now know that theoretical entities, such as phlogiston, caloric, aether, and the like, do not exist, without having to rely on abandonment as an indicator of falsity or nonexistence. If antirealists were to take this line, however, they would run the risk of admitting that theoretical knowledge in science is possible, which is, of course, something that antirealists would not want to admit. For if we know that, say, there is no caloric substance, then we have theoretical knowledge, namely, we know that 'there is caloric substance' is false (alternatively, we know that 'there is no caloric substance' is true). To avoid admitting the possibility of theoretical knowledge, then, antirealists have to take abandonment of a scientific theory or a theoretical posit as an indication of falsity or nonexistence. That is why antirealists often use locutions like "taken to be false by the current lights" (Saatsi 2005, 1092) and "our current best theory [...] suggests ..." (Wray 2015, 62). ${ }^{12}$

Of course, the history of science still provides some examples of dead scientific theories and abandoned theoretical posits. But we must not let these select examples mislead us into accepting the "history of science as a graveyard of theories" picture. For to give more weight to anecdotal evidence than to statistical evidence is a mistake in inductive reasoning known as "overemphasizing anecdotal evidence" or "misleading vividness" (Salmon 2013, 151). To rigorously test the "graveyard picture," then, we must look at patterns, not anecdotes; otherwise, we risk being guilty of confirmation bias and cherry-picking evidence. What the aforementioned new lines of evidence suggest is that we have let a few vivid examples of dead scientific theories (e.g., the caloric theory of heat) and abandoned theoretical posits (e.g., phlogiston) mislead us into thinking that they are typical of science as a whole.

\section{More objections and replies}

In this section, I will consider three additional objections to my argument. The first objection is a methodological one, i.e., it is supposed to point to a problem with the methodology I have employed to test the "graveyard picture." According to this objection, theoretical terms, such as 'atom' and 'planet', have changed their referents over time. For example:

Whereas Ptolemaic astronomers used the term "planet" to denote wandering stars, that is, those "stars" that are not fixed stars, Copernicus used the term "planet" to denote a celestial body that orbits the sun (Wray 2011, 25).

\footnotetext{
${ }^{12}$ On the problem with using such locutions in the context of pessimistic inductions from the history of science, see Devitt $(2011,288)$ and my $(2013,3214-3215)$.
} 
Given this sort of reference change, it is likely that, when contemporary scientists use a theoretical term $t$, they do not refer to what their predecessors referred by using $t$, or so the objection goes.

I think that this objection is misguided for the following reasons. First, this objection presupposes that reference is fixed by descriptions. As Reimer and Michaelson (2014) point out, however, "many [contemporary philosophers] found [the descriptivist theory of reference] ultimately implausible." In fact, like many other philosophers, scientific realists have mostly abandoned the descriptivist theory of reference in favour of some version of a causal theory (Ladyman 2011, 88). As Sankey $(2008,64)$ puts it, if "reference is determined by means of various causal and other pragmatic relations which speakers enter with their environment in the course of linguistic interaction with the world," then "the reference of a term may be unaffected by variation of sense."

Second, even if there are a few examples of theoretical terms whose referents have changed over time, we must not be hasty in generalizing from these few examples. So as not to be misled by the vividness of a few examples, we need to know that such examples are representative of scientific change as a whole. In that respect, it is worth noting that 'planet' and 'atom' may not be good examples of reference change in science, given the distinction between speaker's reference and semantic reference (Mizrahi 2015a, 374). This is not to say that the reference of theoretical terms is not a problem that scientific realists have to deal with (see, e.g., Papineau 2010). But since I am not trying to defend scientific realism, I will leave this issue to the realists. In this paper, I am only concerned with the pessimistic induction; more precisely, with whether there is compelling evidence for the "graveyard picture" based on which we should expect current scientific theories and/or theoretical posits to be abandoned.

The second objection is a philosophical one, i.e., it is supposed to point to a problem with the way I have interpreted the conclusion we should draw from the "graveyard picture." According to this objection, the conclusion we should draw from the "graveyard picture" is not that current theories will (probably) end up in the graveyard (Chakravartty 2008, 152) but rather that current theories could (possibly) end up in the graveyard.

This objection is also misguided for the following reasons. First, this objection seems to make the "graveyard picture" redundant. I do not think anyone would deny that it is possible that currently accepted scientific theories and theoretical posits will be abandoned in the future. There is no need to invoke historical evidence to support such a claim about what is merely possible (as opposed to what is probable).

Second, and as a consequence of making the "graveyard picture" redundant, this objection turns the pessimistic induction from an inductive argument about what is probable to a conceivability argument about what is merely possible. The problem, however, is that claims about what is merely possible are much weaker than claims about what is probable. After all, just as it is possible that a theoretical posit $x$ will be abandoned in the future, it is also possible that $x$ will be retained. Either way, without an inferential bridge from possibility to actuality, such claims about what is possible do not seem to tell us much about the actual enterprise of science. 
The third objection is a dialectical one; that is, it does not purport to point to a flaw in my argument but rather to the fact that my argument is not the sort of argument that is likely to convince an antirealist. According to this objection, one adopts antirealism about scientific theories and theoretical posits not only because of the pessimistic induction but also because of the underdetermination of theory by evidence. There are several versions of the argument from the underdetermination of theory by evidence in the literature on scientific realism. According to Psillos $(1999,162)$, for example, the argument is supposed to run as follows:

two theories which are observationally indistinguishable, i.e., they entail exactly the same observational consequences, are empirically indistinguishable, too, being equally well supported by the evidence. Hence, the argument concludes, there are no positive reasons to believe in one rather than the other. [...] Since, the argument goes on, for any theory which entails the evidence there are incompatible but empirically indistinguishable rivals, it follows that no theory can be reasonably believed to be (approximately) true.

Assessing the argument from underdetermination of theory by evidence is a task that is beyond the scope of this paper. ${ }^{13}$ For present purposes, it is enough to point out that there is a tension between the argument from underdetermination of theory by evidence and the pessimistic induction. That is to say, if theories are underdetermined by evidence, and historical evidence is evidence, then antirealism is underdetermined by the pessimistic induction, since antirealism is a theory and the pessimistic induction aims to support antirealism with historical evidence. In other words, the following is an inconsistent triad:

(1) The pessimistic induction

(2) Scientific antirealism

(3) Underdetermination of theory by evidence

Since (1) is supposed to provide historical evidence for (2), which is a philosophical theory about science, and (3) says that theories are underdetermined by evidence, an antirealist cannot endorse (1) and (3) without thereby being committed to the claim that (2) is underdetermined by (1). Indeed, the fact that scientific realists think that the history of science provides evidence for realism, whereas antirealists think that it provides evidence for antirealism, suggests that these two theories, namely, scientific realism and antirealism, are underdetermined by the historical evidence. $^{14}$

\section{Conclusion}

In this paper, I have presented new lines of evidence that are at odds with the pessimistic picture of the history of science as a graveyard of dead scientific theories and abandoned theoretical posits. These new lines of evidence include:

\footnotetext{
${ }^{13}$ For a book devoted to this task, see Bonk (2008). See also Okasha (2002) and Ivanova (2010).

${ }^{14}$ See my (2015b) where I argue that the case histories Stanford (2006) uses in support of his New Induction are indeterminate between antirealist and realist interpretations. In other words, antirealism is underdetermined by the historical evidence presented by Stanford (2006).
} 
E1: Random samples of scientific theories and theoretical posits turn up significantly more live theories and accepted posits than dead theories and abandoned posits (Tables 1, 2, and 3).

E2: Bibliometric data show that there are dominant theoretical posits that continue to figure prominently in the scientific literature (Figures 1, 2, and 3).

E3: Chronological data show that there are stable theoretical posits that have been in use by practitioners in the relevant fields for more than two centuries (Figure 4).

My overall argument can be summed up as a disconfirmation of the "graveyard picture" as follows:

1. If the history of science were a graveyard of dead theories and abandoned posits, then E1, $\mathrm{E} 2$, and $\mathrm{E} 3$ would not be the case.

2. E1, E2, and E3 are the case.

Therefore,

3. It is not the case that the history of science is a graveyard of dead theories and abandoned posits. $^{15}$

When rigorously tested against the historical record, I submit, the pessimistic picture of the history of science as a graveyard of dead scientific theories and abandoned theoretical posits may turn out to be no more than a philosophers' myth.

\section{Acknowledgments}

I am grateful to two anonymous reviewers of International Studies in the Philosophy of Science for helpful comments on an earlier draft. Special thanks are due to the editor, James W. McAllister.

\section{References}

Bonk, Thomas. 2008. Underdetermination: An Essay on Evidence and the Limits of Natural Knowledge. Dordrecht: Springer.

Chakravartty, Anjan. 2007. A Metaphysics for Scientific Realism: Knowing the Unobservable. Cambridge, MA: Cambridge University Press.

Chakravartty, Anjan. 2008. "What You Don't Know Can't Hurt You: Realism and the Unconceived." Philosophical Studies 137 (1): 149-158.

Chang, Hasok. 2011. "The Persistence of Epistemic Objects through Scientific Change." Erkenntnis 75 (3): 413-429.

\footnotetext{
${ }^{15}$ See footnotes 9,10 , and 12 .
} 
Cohen, Bernard, I. 2001. Revolution in Science. Cambridge, MA: Harvard University Press.

Doppelt, Gerald. 2007. "Reconstructing Scientific Realism to Rebut the Pessimistic Metainduction." Philosophy of Science 74 (1): 96-118.

Fahrbach, Ludwig. 2011. "How the Growth of Science Ends Theory Change." Synthese 180 (2): 139-155.

Fahrbach, Ludwig. 2016. "Scientific Revolutions and the Explosion of Scientific Evidence." Synthese. doi:10.1007/s11229-016-1193-y.

Frost-Arnold, Greg. 2011. "From the Pessimistic Induction to Semantic Antirealism." Philosophy of Science 78 (5): 1131-1142.

Frost-Arnold, Greg. 2014. "Can the Pessimistic Induction Be Saved from Semantic Anti-realism about Scientific Theory?" British Journal for the Philosophy of Science 65 (3): 521-548.

Govier, Trudy. 2014. A Practical Study of Argument. $7^{\text {th }}$ Ed. Boston: Wadsworth.

Graham, Daniel, W. 2013. Science before Socrates: Parmenides, Anaxagoras, and the New Astronomy. New York: Oxford University Press.

Harker, David. 2015. Creating Scientific Controversies: Uncertainty and Bias in Science and Society. Cambridge: Cambridge University Press.

Harrison, Peter. 2015. The Territories of Science and Religion. Chicago: University of Chicago Press.

Heilbron, John L., ed. 2003. The Oxford Companion to the History of Modern Science. New York: Oxford University Press.

Ivanova, Milena. 2010. "Pierre Duhem's Good Sense as a Guide to Theory Choice." Studies in History and Philosophy of Science 41 (1): 58-64.

Ladyman, James. 2011. "Structural Realism versus Standard Scientific Realism: The Case of Phlogiston and Dephlogisticated Air." Synthese 180 (2): 87-101.

Lange, Marc. 2002. "Baseball, Pessimistic Inductions and the Turnover Fallacy.” Analysis 62 (4): 281-285.

Laudan, Larry. 1981. “A Confutation of Convergent Realism.” Philosophy of Science 48 (1): 1948.

Law, Jonathan and Rennie, Richard., eds. 2015. A Dictionary of Physics. Seventh Edition. New York: Oxford University Press.

Lewis, Peter. 2001. "Why the Pessimistic Induction is a Fallacy." Synthese 129 (3): 371-380.

Lipton, Peter. 2005. "The Truth about Science." Philosophical Transactions of the Royal Society B 360: 1259-1269. 
McMullin, Ernan. 2002. "The Origins of the Field Concept in Physics." Physics in Perspective 4 (1): 13-39.

Mizrahi, Moti. 2013. “The Pessimistic Induction: A Bad Argument Gone Too Far.” Synthese 190 (15): 3209-3226.

Mizrahi, Moti. 2015a. “Kuhn's Incommensurability Thesis: What's the Argument?” Social Epistemology 29 (4): 361-378.

Mizrahi, Moti. 2015b. "Historical Inductions: New Cherries, Same Old Cherry-Picking." International Studies in the Philosophy of Science 29 (2): 129-148.

Müller, Florian. 2015. "The Pessimistic Meta-Induction: Obsolete through Scientific Progress?" International Studies in the Philosophy of Science 29 (4): 393-412.

Okasha, Samir. 2002. "Underdetermination, Holism, and the Theory/Data Distinction," Philosophical Quarterly 52 (208): 303-319.

Oxford Reference. 2003. "The Oxford Companion to the History of Science." Accessed March 10. http://www.oxfordreference.com/view/10.1093/acref/9780195112290.001.0001/acref$\underline{9780195112290 .}$.

Papineau, D. 2010. Realism, Ramsey Sentences and the Pessimistic Meta-Induction. Studies in History and Philosophy of Science 41 (4): 375-385.

Park, Seungbae. 2011. "A Confutation of the Pessimistic Induction.” Journal for General Philosophy of Science 42 (1): 75-84.

Park, Seungbae. 2014. “A Pessimistic Induction against Scientific Antirealism.” Organon F 21 (1): 3-21.

Psillos, Stathis. 1999. Scientific Realism: How Science Tracks Truth. New York: Routledge.

Rennie, Richard., ed. 2016. A Dictionary of Chemistry. Seventh Edition. New York: Oxford University Press.

Reimer, Marga and Michaelson, Eliot. 2014. "Reference." The Stanford Encyclopedia of Philosophy (Winter 2014 Edition), Edward N. Zalta (ed.), URL = $<$ http://plato.stanford.edu/archives/win2014/entries/reference/>.

Ruhmkorff, Samuel. 2014. "Global and Local Pessimistic Meta-Inductions." International Studies in the Philosophy of Science 27 (4): 409-428.

Salmon, M. H. 2013. Introduction to Logic and Critical Thinking. $6^{\text {th }}$ Ed. Boston, MA: Wadsworth.

Saatsi, Juha. 2005. "On the Pessimistic Induction and Two Fallacies." Philosophy of Science 72 (5): 1088-1098. 
Saatsi, Juha. 2015. "Historical Inductions, Old and New." Synthese. DOI 10.1007/s11229-0150855-5.

Sankey, Howard. 2008. Scientific Realism and the Rationality of Science. Burlington, VT: Ashgate Publishing Co.

Schulz, Kathryn. 2011. "The Pessimistic Meta-Induction from the History of Science.” Edge. https://edge.org/response-detail/11135.

Sorensen, Roy. 2013. "Veridical Idealizations." In Melanie Frappier, Letitia Meynell, and James Robert Brown (eds.), Thought Experiments in Philosophy, Science, and the Arts (pp. 30-52).

New York: Routledge.

Springer. 2017. "Springer Archives.” Accessed March 10. http://resource-

cms.springer.com/springer-cms/rest/v1/content/10704936/data/v4/Springer+Archives+Brochure.

Springer Exemplar. 2017. "About.” Accessed March 10.

http://www.springerexemplar.com/about.aspx.

Stanford, Kyle P. 2006. Exceeding Our Grasp: Science, History, and the Problem of Unconceived Alternatives. New York: Oxford University Press.

Stengers, Isabelle. 2000. The Invention of Modern Science. Translated by Daniel W. Smith. Minneapolis: University of Minnesota Press.

Varvoglis, H. (2014). History and Evolution of Concepts in Physics. Dordrecht: Springer.

Vickers, Peter. 2013. “A Confrontation of Convergent Realism.” Philosophy of Science 80 (2): 189-211.

Wray, K. Brad. 2011. Kuhn's Evolutionary Social Epistemology. New York: Cambridge University Press.

Wray, K. Brad. 2013. "The Pessimistic Induction and the Exponential Growth of Science Reassessed.” Synthese 190 (18): 4321-4330.

Wray, K. Brad. 2015. "Pessimistic Inductions: Four Varieties." International Studies in the Philosophy of Science 29 (1): 61-73. 